\title{
PREMIO JUAN RULFO A TOMÁS SEGOVIA
}

$\mathrm{T}$ omás Segovia recibió en la pasada Feria del libro de Guadalajara (noviembre, 2005) el prestigioso premio Juan Rulfo. En su entrega se dieron varios elementos que hay que destacar. Se premió a uno de los grandes escritores contemporáneos en lengua castellana, se premió a un autor no ajeno pero sí al margen de los círculos establecidos de la cultura. Sagaz polemista e inteligente ensayista, extraordinario poeta y narrador, Segovia merece éste y todos los premios que se le hayan dado o se le den. En la premiación su discurso - que aquí se publica-mostró que ya que le daban la tribuna no quería decir sólo elementales formas de cortesía para salir del paso, sino que escribió un penetrante texto sobre lo que significa ser premiado. Otro heterodoxo, el divertido herudito (sí, con h, porque tiene algo de heroísmo) y filólogo -todos estos calificativos parecen una contradicción juntos-Antonio Alatorre hizo un apasionante retrato del premiado, y el lingüista Luis Fernando Lara y el médico Haroldo Díes, ambos amigos cercanos de Segovia, trazaron el itinerario de eso precisamente: su amistad. La publicación de este dossier sirve para rendir homenaje al autor de Cuaderno del nómada, Alegatorio y Otro invierno.

\section{Discurso de Guadalajara}

Hace casi cuatro meses que supe que me habían dado el premio Juan Rulfo, y todavía ahora, cada vez que pienso en ello, no puedo dejar de sentir la misma sorpresa que sentí entonces. La sorpresa, por 

DOSSIER

supuesto, no excluye la gratitud, más bien al contrario: un buen regalo que no tenga algo de sorpresa parece que le falta algo, una ligereza, una alegría. Pero quien recibe un regalo inesperado no puede dejar de pensar, aunque sólo sea durante algunos segundos, que tal vez es un error y que acaso el regalo no es sólo inesperado, sino también inmerecido. Supongo que nadie irá a pensar que estoy dándome baños de modestia, o sea presumiendo de modesto, esa cosa tan groseramente contradictoria. Mi sorpresa agradecida no tiene que ver con mis méritos o falta de méritos. Buenos escritores, o sea escritores que cuentan con cierto número de admiradores más o menos espontáneos, hay todos los que ustedes puedan imaginar, y el que más y el que menos, muchos de ellos merecen algún premio, si es que los premios han de existir y si es que pueden merecerse. Por lo menos es claro que la mayoría de ellos trabajan, se esfuerzan, estudian, luchan, sufren y hacen otras cosas igualmente meritorias.

Repito: no se trata de méritos. Mi sorpresa no es que se dé un premio a un escritor con los méritos que pueda tener o dejar de tener yo, sino que ese escritor sea yo. Quiero decir: un escritor con mis características, que no es lo mismo que mis méritos. $\mathrm{O}$ con algunas de mis características, porque lo sorprendente no es que se me premie a mí personalmente, sino a alguien como yo.

Yo no estoy tan seguro de que los escritores y artistas merezcamos que se nos premie, se nos apoye, se nos ayude, se nos financie y se nos privilegie de diferentes maneras. $\mathrm{O}$ en todo caso no más que a cualquier otra clase de ciudadanos. Y menos aún de que las autoridades de los diferente países tengan la obligación de fomentarnos y protegernos así, cuando hay tantas cosas obviamente más importantes para los intereses de esas autoridades o de esa sociedad que se supone que representan, y que yo no veo que merezcan menos que nosotros ser promovidas y alentadas. Pero si esos premios y estímulos han de existir de cualquier manera y no están a fin de cuentas enteramente injustificados, seguramente comparten algunos rasgos generales o tendencias implícitas que todos reconocemos más o menos inconscientemente o que damos por descontados sin pensar en ellos. Cuando alguien es escogido para 
uno de esos 'estímulos', casi todo el mundo habla de 'reconocimiento' -merecido reconocimiento, suelen añadir. A mí no me convence esa expresión. Ese uso del verbo reconocer hace pensar enseguida en reconocer los propios errores, o más bien en conceder algún punto al contrincante sin verdadera convicción, o ceder a los argumentos del otro como quien pacta una tregua. Parece que reconocer a un escritor es siempre reconocerlo a regañadientes, como si los que lo premian -y la gente en general- hubieran estado mirando obstinadamente a otro lado y por fin hubieran tenido que 'reconocer' a pesar suyo que allí había un escritor. Los que nos felicitan por ese 'merecido reconocimiento' parece que nos dijeran: "Yo siempre estuve contigo; por fin hemos ganado; por fin han tenido que reconocer que eres alguien; ahora tendrán que tragarse sus palabras."

Yo desde luego no me siento así. Creo más que nadie en el reconocimiento -anagnórisis en griego-, pero no en ese sentido. Creo también que hay zonas, corrientes, actitudes que ocupan el centro y otras las márgenes, y que sus relaciones son movibles, dinámicas, en gran parte antagónicas y en muchos aspectos polémicas. Pero esa manera francamente belicista de plantear la polémica no me parece sensata. Ni todas las zonas centrales son excluyentes ni todas las zonas marginales son marginadas. Precisamente en lo primero que pienso cuando me sorprende que me premien es en que yo soy probablemente un escritor marginal pero no marginado. En ese sentido, yo me he sentido siempre 'reconocido'. Más de lo que hubiera podido esperar. No reconocido masivamente, por supuesto, pero ¿quién ha dicho nunca que el reconocimiento sea cosa cuantitativa? Un premio literario, por ejemplo -y yo no he recibido muchos, pero en todo caso más de uno, como ustedes tal vez saben-, un premio literario puede suponerse que recoge el sentir de una mayoría de lectores, pero de hecho lo decide un grupo muy reducido de personas, un jurado selecto que también puede suponerse que no se pliega a las preferencias de los lectores, sino que justamente quiere sugerirles o contagiarles innovaciones o cambios en sus gustos y revelarles valores insospechados. Mi caso 

DOSSIER

podría ser de ésos, puesto que mis libros nunca se han vendido ni siquiera medianamente bien.

Pero ésa es la cosa, o como dijo Cantinflas, ahí está el detalle. Yo siempre he publicado en editoriales marginales, y sin embargo mi obra ha acabado por transminar en alguna que otra editorial central. Lo cual a su vez me sorprende, ya pueden imaginárselo, porque ese logro, o esa suerte, ese 'reconocimiento', no impide que tenga que seguir recurriendo a editoriales marginales para dar a conocer mis cosas. Y entonces no tengo más remedio que pensar que esta situación peculiar, este estar en sitios a los que no pertenezco, este asomarme al centro desde las márgenes, este pasearme por el centro sin perder mi marginalidad y esta fidelidad a las márgenes sin aislarme de la centralidad es lo que puedo llamar mi destino. Yo, en efecto, nunca me he aposentado en el centro de mi época, de mi cultura, de mi ideología. Esta época mía, nuestra, eso que solemos llamar la modernidad, nace con el triunfo de la desconfianza frente al pasado. La duda, ese hábito occidental, que empieza en Europa, con Descartes, siendo metafísica y trascendental, acaba aterrizando en la realidad y poniendo en duda la religión, el origen divino del poder, la autoridad de la tradición y de las creencias. Esa modernidad no tarda en afianzarse rechazando todo pasado, del que no sólo desconfía sino del que además reniega.

Yo también, naturalmente, soy moderno: viviendo en la época en que vivo, no puedo dejar de desconfiar de la religión, más virulenta hoy que en tiempos de la Ilustración; del origen, divino o no, del poder; de la autoridad tradicional. Pero esa ideología recibida, unida a las circunstancias particulares de mi vida, a mí me llevó bastante pronto a desconfiar no sólo del pasado, sino también del presente y del futuro. Las grandes creencias de mi época, la exaltación de lo nuevo, la fe en el progreso, en especial identificado con el progreso tecnológico, la orgullosa convicción de que sólo ahora entendemos la realidad, la desacralización de la vida, manifestada cotidianamente en la banalización del cuerpo, del sexo y del deseo, y sobre todo nuestras prohibiciones explícitas o implícitas: la prohibición de pedir cuentas al conocimiento científico, a la idea establecida de democracia, al arte y a la 
poesía, todos esos presupuestos compartidos yo los miro con la misma desconfianza que las creencias y prohibiciones de la Edad Media o del Barroco. Eso también da un sentido diferente a mi desconfianza del pasado. En lugar de mirar el pasado como el lastre del progreso, la resistencia a la innovación, la ceguera o la cobardía que estrangula el cambio (que siempre es adelanto y nunca retroceso), el peso muerto del que hay que liberarse para entregarse al fervor de lo nuevo; en lugar de eso, decía, el que desconfía de esa desconfianza misma toma distancia frente al pasado no para condenarlo y rechazarlo sino para tratar de entenderlo, porque el pasado, lo mismo que el presente, se equivoca sobre sí mismo si no toma distancia.

En la literatura y el arte, por ejemplo, puesto que se supone que ése es mi terreno, a mí me enseñaron, como a todos los modernos, que es ridículo preguntar qué quiere decir un poema, un cuadro, una escultura. Hay que cuidarse mucho de quedar como un pobre bobo inculto y desinformado haciendo esa ingenua pregunta. A mí, desde que empecé a escribir, siempre me pareció que era demasiado fácil protegerse así del juicio del lector. Era yo muy joven cuando me rebelé contra la famosa anécdota de las ostras. Un pintor moderno está enseñando sus cuadros a un buen burgués, zafio por supuesto, que le dice que no entiende su pintura. El pintor le pregunta: "¿A usted le gustan las ostras? -Sí, mucho. - ¿Y las entiende?" No sé qué contestaría el pobre burgués, pero sé qué contestaría yo: Precisamente por eso no las enmarco y las cuelgo en mi sala o voy a contemplarlas al museo -ni pago por ellas medio millón de dólares, cosa que también tiene su importancia.

En cuanto a mí, siempre me esforcé por hacer una poesía interpretable, una poesía que tal vez algún lector encuentre difícil, porque no se trata de que sea mejor lo fácil que lo difícil, ni tampoco de lo contrario, pero una poesía que no sea impenetrable. Explicaré un poco en qué sentido digo interpretable. Interpretar no es ni definir, ni traducir a un lenguaje diferente, ni añadir significaciones arbitrarias, ni anexar lo interpretado a una teoría preexistente o creada ad hoc. Interpretar es poner en contexto. Un mensaje recibido se puede descifrar, en el sentido de 

DOSSIER

descodificar, fuera de contexto, a condición de que dispongamos del código. Pero no se puede interpretar fuera de contexto. Esa burla que hacen los bien informados al pobre ingenuo que pregunta qué quiere decir una obra de arte o de poesía es un verdadero chantaje intimidatorio, con el que se coloca al arte y la literatura a salvo de todo contacto con la impura vida de los impuros mortales, más allá de todo contexto, absoluta y sublimemente fuera de contexto.

Yo soy tan mal militante de la modernidad, que encuentro perfectamente legítimo que un lector me pregunte qué quiere decir un poema mío. No es fácil contestar, por supuesto, y es mucho más cómodo sentenciar que la poesía no se explica. Como las ostras. La respuesta muchas veces es decepcionante, y eso parece justificar que se descarte toda respuesta. Pero hay preguntas cuya respuesta es imperfecta o incluso imposible, por lo menos en el sentido de que nunca puede cerrarse y concluirse, y que son sin embargo preguntas legítimas. Sería muy grave por ejemplo que nos ridiculizaran por preguntar por el sentido de la vida, aunque es claro que nunca podremos acabar de contestar. O que nos dijeran que es muestra de incultura pedirle cuentas al gobierno, aunque bien sabemos que no nos las dará.

Pero yo soy todavía más díscolo en el redil de la modernidad. Creo en el uso de la literatura y el arte. Para empezar, en el uso en el sentido que tiene el término para los lingüistas. El uso en ese sentido es muy exactamente la puesta en contexto, y para los lingüistas los elementos de la lengua no tienen sentido mientras no estén puestos en contexto. Y conste que el contexto no son sólo otros elementos lingüísticos, también es con-texto el mundo al que se confronta el texto -contexto situacional lo llaman ellos. Y si el poema toma sentido en el contexto del mundo real, es claro que al lector le sirve para iluminar o siquiera confrontar ese mundo real. Ese uso de la poesía, que es su verdadera interpretación, es el que practicamos por ejemplo cuando, en el contexto de una emocionante bocanada que sale de algún viejo portal, llamamos a eso, casi involuntariamente, 'el santo olor de la panadería'; o cuando, al recordar un palpitante episodio de nuestra infancia, nos sorprendemos susurrando "Mi frente aún está roja del 
beso de la Reina"; o cuando, al acercarnos a los lugares inquietantes de nuestros abuelos, escuchamos una voz casi ultramundana que nos está contando "Vine a Comala porque me dijeron que aquí murió mi padre." Eso es poner en práctica la poesía, porque el uso es una praxis, la implicación del sentido en el mundo real, el abrazarse del pensamiento con 'la rugosa realidad', para decirlo con palabras de Rimbaud, usando así un poema más.

Puede decirse pues que aunque yo tenga alguna presencia, alguna nebulosa existencia en los lugares centrales de la nuestra modernidad, no pertenezco a ellos porque no comparto sus fes más recalcitrantes. No creo que el arte y la poesía sean un mundo aparte donde no se aplican las exigencias, las búsquedas, las preguntas y los anhelos del resto de la vida humana. Creo que los entendidos de este siglo y pico han creado un sistema especulativo de segundo nivel, donde las obras de poesía y arte valen no por su contenido, sino por su pertenencia a las estructuras de ese segundo nivel, un sistema de escuelas, de ismos, de corrientes, de modas, de competencia inventiva, y muy significativamente de galerías de arte, museos, casas de subasta y listas de precios. Ese sistema, refinadamente constituido y perfectamente anclado en los medios dirigentes, tiene su propia coherencia y sus propias reglas e incluso leyes, y no es que a mí se me escape, lo entiendo perfectamente, incluso la especulación conceptual con que se justifica, pero yo, el MOMA me perdone, sigo buscando un contenido en el arte y la poesía. Me parece que en el arte abstracto, por ejemplo, lo verdaderamente abstracto no es el cuadro, es el sistema especulativo sin el cual no se justifica. O sea que no es que sea tan ridículo preguntar qué significa; no es que el arte no se explique, todo lo contrario: es que la respuesta no está en el cuadro, está en la teoría que lo explica, justamente, y sin la cual no sería cuadro.

¿No es de esperarse que alguien que piensa así se sorprenda de que le den premios? Todo parece indicar que he sido reconocido, o más bien que estoy, que siempre he estado reconocido, pero ¿significa eso que es reconocida también mi postura ante mi tiempo y mi medio? ¿Puedo decir que por lo menos algo hay de eso? En alguna 

DOSSIER

época estuve tentado de llamar a mi postura 'la otra modernidad'. Pero no es eso. No se trata de pasar de una a otra modernidad como quien pasa del PRI al PAN, de los republicanos a los demócratas, del Pumas al América. Lo mismo puede decirse que hay una sola modernidad o que hay todas las que uno quiera. Pero a una persona que piensa como yo, sin duda hay que ponerla también en contexto. Tendría que ser en el contexto de mi vida donde se expliquen, quiero decir se entiendan, mis maneras de pensar. Desde mi nacimiento, yo he estado siempre dentro y fuera de los lugares, de los grupos, de las familias, de las comunidades donde he vivido. La orfandad y el exilio son las manifestaciones más fácilmente reconocibles de esa peculiaridad, pero son sólo dos entre muchos otros ejemplos. Si he vivido tantos desarraigos, ¿cómo no sentirme también más o menos desarraigado del suelo del pensamiento compartido en el mundo y la época que me tocó vivir? Hay otras posturas generales de mi tiempo con las que no he podido nunca comulgar: la fe en las raíces, en las nacionalidades, en la identidad, en la bondad sin sombras de las comunidades. Dudo también muchísimo de los efectos benéficos automáticos de la sociedad de mercado, de la ideología darwinista en política, de la necesidad de

100 fundar toda la actividad humana en la competitividad, como la llaman, y de otros aspectos del consenso de nuestras figuras más destacadas, pero sé que estas posturas en particular las comparto con mucha más gente que mis actitudes frente a la modernidad en arte y literatura, o frente a los valores intocables que acabo de mencionar.

Siempre he envidiado la sabiduría de las mujeres, que me parece, si no originada, por lo menos históricamente alimentada por siglos de marginalidad y discriminación. La mirada desde las márgenes ve cosas que no son visibles desde el núcleo. Quien se mueve en el centro de su sociedad no puede ver que el rey está desnudo. No me comparo con las mujeres, pero yo también he conocido desde la infancia pequeñas marginalidades y discriminaciones de la sociedades donde me ha tocado vivir. Que en este siglo que empieza los arraigados van a tener que contar muchísimo con los desarraigados es lo que acabamos de comprobar no sin escalofrío en las barriadas de Francia y otros países 
europeos. Mi caso no es de ésos, desde luego. Lejos de ser apaleado por la gendarmería, yo soy en todo caso un desarraigado premiado. Cierto que tampoco me he entregado a la violencia y el caos, sino que más bien he estado acumulando méritos, o eso dicen los amigos que me felicitan ahora. Sería ridículo pensar que conmigo el Premio Juan Rulfo premia todos los desarraigos, incluyendo el de los violentos de los suburbios europeos. Pero si algún desarraigo, por largamente meritorio y reconocido que haya sido, entra conmigo en este lugar central, ¿no les parece comprensible que a mi gran gratitud se mezcle alguna sorpresa?

Tomás Segovia

Señoras y señores:

Es un gran honor para mí... Estas seis palabritas habrán sido, seguramente, el comienzo de centenares de miles, millones quizá, de alocuciones y discursos, sinceros algunos, otros insinceros. En todo caso, "Es un gran honor para mí" ha degenerado en fórmula retórica, frase de cajón, cosa hueca. Y, sin embargo - ¡lo que es la tenacidad de los lugares comunes, su enorme fuerza de inercia!--, debo confesar que fueron esas seis palabritas las que me vinieron a la cabeza en el momento de ponerme a escribir esto que estoy leyendo. Y es que, en verdad, así es: me siento honrado, privilegiado, feliz por haber sido escogido para hablar aquí y ahora de Tomás Segovia. Porque no fui escogido por ningún comité organizador, sino por el propio Tomás Segovia. Me hizo la invitación por teléfono, desde Madrid. Tal vez debí preguntarle por qué me invitaba a mí y no a otro de los muchos amigos y lectores que tiene, pero no lo hice, sino que acepté rápidamente, como temeroso de que otro se me adelantara. Mientras le decía que sí, me bailaba en la cabeza este pensamiento: ¡Qué oportunidad perfecta para decir en público lo mucho que quiero y admiro a Tomás! Y, para explicar el qué y el porqué del "gran honor", necesito decir, aunque sea con medias 